\title{
Footing in Presidential Debate of Indonesian Election
}

\author{
Latif Amrullah \\ \{latif.amrullah@hud.ac.uk\}
}

University of Huddersfield, Quensgate, Huddersfield, HD1 3DH, United Kingdom

\begin{abstract}
This paper attempts to explore further the unusual action in the first-round presidential debate of Indonesian election encounter by applying Goffman's interactional approach. It governs the notion of frame and footing. This viewpoint shows that, albeit there is politically a power asymmetry between the two candidates, they create an interactive symmetry in which one of them is de-ratified by spontaneous action. Speaking interaction between the moderator and the two candidates signifies two essential facts: power asymmetry in terms of conversation arrangement and interactive asymmetry in terms of turn taking scheme. The two candidates shift their footing as the moderator of the presidential debate allows them to do so. The Goffmanian perspective also shows the effect of public situational debate in this encounter.
\end{abstract}

Keywords: frame, footing, Goffman, participation framework, presidential debate

\section{Introduction}

The main purposes of this study are the curiosity to understand how a nationally live broadcasted presidential debate unexpectedly shows an eccentric body gesture from one of the candidates and to examine the following reactions of the audience and the self-control of the doer in the situational conversation. It means that there is a correlation between speech and behaviour involving speech [1]. One way to discuss this matter is by looking deeply into the foundation of encounter and the interaction among the participants during the process of talk, in this case, the presidential debate. Besides, Goffman has also served a great contribution in the studies of media by proposing the concepts of frame, footing, front and back region [2] as well as the basic notion on control of information and models of ritual in the process of interaction [3]. The study of presidential debates attracts the focus of expertise in the field of politics, communication, economic, and language because this debate relates to national issues and international relations which, in turn, will lead the nation to its journey. However, for the public as voters, it is their rights to know and understand who the candidates are, their characters, and their programmes [4]. All that initial information will determine their potential decision on the election day and improve the knowledge of voters [5]. The prominent of presidential debates becomes a common awareness of candidates as they need gaining as many votes as possible to win the election as what John F. Kennedy did on the first history of a presidential debate in September 1960 [6]. It is impossible to conduct debates by inviting people to come and sit together at the same time. For this rationale, broadcasting companies take their part. 
For the presidential race, a candidate usually has a special task force which covers all the needs for the campaign; framing the candidate into the best appearance all the time and tackle the incoming issues. Mass medias also have their position to frame the news appearing in their headlines in accordance to the journalism ethics. While written media has less effect on the public decision, television can easily cover all the limitations and provide the public with a real experience of attending presidential debates lively. In this stage, multiple framings take place which will result in doubtful genuine broadcasting: each candidate constructs normative questions and answers while television crews are trying to depict the most convincing moving pictures. There will possibly be a bias of dramatic actions and visible message, leaving behind the essential purpose of discourse [4]. Among those contradictions, the results are unpredictable. In this modern era of technology, moreover, social media platform permeates the barriers of time and space. As an example, people can give comments on Twitter at real time as they are watching the presidential debates [7].

Before the presidential debates, it is hard to extrapolate what will happen in post-debate conversations since, during the debates, the candidates' responses and convincement will influence the voters' preferences which result in reinforcement effects [8]. It can also be possible that presidential debates have nothing useful owing to fixed loyalties decision already of the voters [9]. Right after the first presidential debate in 1960, as a new stage in a presidential run at that time, surprisingly there were many conversations among people on the discussion of the debates [4]. In 2008 US presidential run, Obama gained a rocketing popularity percentage from the swing voters after the first presidential debate. He could take down the arguments proposed by McCain [10]. Presumably, it is Obama's paralinguistic aspects which helped him to get promising votes. These post-debate conversations rise among the public as the result of concerns for the political and thematic process of the debates itself. It also happens in Indonesian presidential run which has finished recently.

The results of Indonesian's general election leaves smile and tears among the candidates of those who want to be either the house of representatives in parliament or the president. It is the first time in the history of Indonesian politics that both types of elections are conducted at the same time, not in sequential as previously. For linguists, the race for election - campaigns, propaganda, persuasions - provides abundance of interesting topic to be discussed in many branches of linguistics, to name three as example: language and power, discourse analysis, and pragmatics. Especially for the presidential race, there are plenty of interesting cases that may arise a topic of research: the presidential debate. It is a hot news in mass media since whatever the candidates do or say become the headlines delivered by news anchors and editorials. One of the most noticeable actions in the Indonesian presidential debate, which run five times, is on the first president and vice-president debate. There are two candidates at the time: the incumbent (candidate 01) and the challenger (candidate 02). In the first presidential debate, there is an unexpected body gesture from one of the candidates who becomes the trending topic in online video sharing YouTube, i.e. a dance-like body gesture during other's saying. This phenomeon signifies a transformation of preference from television viewers to YouTube recipients [11]. The popularity of this video gained in the online video sharing is, perhaps, due to the meaning and intention of the doer. It is under Goffman's [12] proposition that the presence of individuals in an encounter carries out some kinds of implication and meaning. To understand the body movement of the candidates, it is insufficient by analysing merely from the previous action, yet the whole context on the interaction is predominant.

During the presidential debate, there is a question-answer session between the two candidates as two moderators assists the floor. The female moderator invites candidates 01 to deliver a question just only in a minute. Candidate 01 raises a statement and asks for 
clarification on the issue that many senator candidates who have ever been incarcerated due to the corruption are nominated again as a member of parliament by candidate 02's party. Moderator gives the next turn to candidate 02 and permits two minutes talk to answer the query. During the reply, he denies the accusation on that case toward his political party. Having spoken for almost two minutes, he considers that the answer is enough. In the next turn, the moderator gives a minute chance for the candidate 01 to respond the prior answer. $\mathrm{He}$ commences the sentence with an apology, and then he restates the previous question that he does not mean to accuse candidate 02 's political party. Suddenly, the challenger wants to interrupt during the incumbent's occasion of speaking. Having known that it is not allowed as what the moderator said, and it creates crowd on the audiences, candidate 02 reacts with an unexpected bodily movement: waving both hands and shoulder together with the facial expression. Having been aware of the current situation, the vice-president candidate tries to massage his companion by putting the hands on his shoulder. Thanks to the moderators who control the conducive situation and freeze the time allocation so that candidate 01 may continue his response. Once he finishes, candidate 02 receives a minute talk to give feedback about the previous response. The emergence of bodily movement by candidate 02 as part of non-vocal activities becomes the focus of this paper in the conversational analysis because vocal and non-vocal activities are closely related in producing actions of interactants [13] or move based on Goffman [12].

The above case involves speaker and hearer which constitute a dyadic model of communication [14], either ratified or bystander participants who then construct an interaction which has been organized based on social constraints [15]. In this situation, the participants audience, moderator, president candidates - are together in a place called as social situation: an environment which enables every individual to be accessible to one another until the finalleave. Not all the participants are taken part in the presidential debate, predominantly the moderator and both candidates have it. The distant between participants and the rights of speaking elaborate to be of what Goffman calls as gathering [1]. There are two kinds of gathering, i.e. focussed and unfocused. The former means the participants are ratified each other as co-participants and go on in the conversation, while the latter means the participants "have not extended to each other the status of co-participants in an open state of talk" $[16, \mathrm{p}$. 145].

During the presidential debate, the moderators manage all sessions: allocating time, allowing speaking, and controlling the floor. The moderators and the candidates are aware of the presence of direct viewers: the candidates, audiences, tv crews; and indirect viewers: tv viewers who are outside the present time and place. This awareness appears to govern their expected behaviour - since some tv stations broadcasts the presidential debate nationally - and constraints of their action [17]. In this interaction, the audience are merely co-presence: nor do they have any rights of speaking in turn taking. This made-up situation is designed in a purpose to achieve what they want to conduct as an encounter.

Goffman [18] explicates the concept of the frame as an occasion which is constructed by the rules of event organisation, and the participants are willing to involve in it. For sure, the purpose of the presidential debate must have been decided long before and - as it is broadcasted through the country - the concepts must have been aligned with the social rules to meet the norms. Therefore, Goffman proposes social occasion as one factor in determining an encounter. Place and time bind the participants through the medium of certain apparatus of social conditions which there is a sequence of opening to end [19]. It is important to understand what people are talking about during the encounter, albeit some limitations are hiding behind it. There are many possibilities of intention among the participants who are 
involved in the social occasion: serious, playful, or chill. It is important to note that there is a possibility of changes of a frame during an encounter owing to "potential for the divergent assumption of frames" [17] among participants.

Changes on frame lead to the notion of footing alteration. Goffman [12, p. 128] dynamically defines footing: "a change in footing implies a change in the alignment we take up to ourselves and the others present as expressed in the way we manage the production or reception of an utterance." The definition of footing [12] covers five aspects: 1) participant's alignment, 2) the projection, 3) a continuum, 4) code-switching, and 5) episode of interaction. Succinctly, following O'Driscoll [17, p. 43], “footing describes a participant's interpersonal and social stance at a particular moment in an encounter, while frame involves a prototype of all participants' stances for an encounter as a whole."

A number of studies have begun to examine the relationship between conversation and the alteration of frame and footing. O'Driscoll [17] and D'hondt [20] concerned the study on changes of footing in the trajectory appeared at courtroom encounter, as well as what Heisterkamp [21] had done in court mediation. In these studies, the judge held a power to govern the conversation and social encounter represents power asymmetry. O'Driscoll also conducted a research on email communication, which results in the public-ization of private offence [22]. On the other word, this study brings inner-world of communication to outerconsumed of talk by inviting the unratified participants to get in. In educational interaction, Ekström [23] investigated peer assessment with the interactive organisation among the teachers. Agha [24] examined the influence of footing alteration manifested in registers through a dynamic social life. Other footing-related researches in education are Skidmore and Murakami [25] which focus on the prosody of teacher-student dialogue; and Cromdal \& Aronsson [26] which concentrates on code-switching in school children play interaction. In a bigger scope of children interaction, Kyratzis and Leon [27] pointed out that the combination of footing, alignment, and scale can possibly help the analysist of micro-macro process of children multilingual interaction. The study of footing in conversational completion was also conducted by Antaki, Diaz\&Collins [28] which demonstrated that footing in Goffman's dimension is alive for participants. Schegloff [29] conducted a research on sequencing structure and conversational openings, as well as Hutchby [30] who specified the research in talk radio show. Those papers indicate a need to understand the various application of frame and footing shift in asymmetrical conversation and the ratification of participants in social encounter. This analysis demonstrates how a nationally live broadcasted presidential debates unexpectedly shows an eccentric body gesture from one of the candidates. Up to this stage, the research has not detailed a clear cut off participation effect in the encounter. The combinations of frame encounters, changes in footing, and the bodily movements create a different perception of social encounter on the recipients. It is also imperative that the following reactions of the audience be paid attention along with the self-control of the doer in the conversational alignment. Therefore, the production and the reception of sounds and gestures during the encounters generate an alteration on emphasising of focal conversation.

\section{Methodology}

The present investigation was carried out by observing a video fragment of the first presidential debates which is held in a hotel ballroom in Jakarta. The video was taken from online video sharing YouTube, either the fragment video which is available in CNN Indonesia 
YouTube account (https://www.youtube.com/watch? $\mathrm{v}=$ wE07fwtm_II) or the full recording of the debates which can be accessed in KompasTV account. The fragment video gains its popularity owing to the unusual bodily movement of the president candidate 02 and his partner (vice-president candidate). Although the videos are published online, there were some tv stations broadcasted the event live at the time of presidential debate was held, which, presumably, tv viewer paid less attention to what has just happened or might be distracted by other scenes. The four-minute fragment video over the whole presidential debate was then transformed into a musical-score format transcription [17]. This format gives a better comprehension of the moving scene and the interactions of verbal and non-verbal among participants in written form simultaneously [31]. In every line, therefore, there is a transcription of speech production and physical reactions of the speaker located under it.

\section{Results and Discussion}

In this social encounter, it is important to comprehend firstly the physical realities surrounding the presidential debate as it is seen in the recording, thus the participants could act properly based on the situation's expectancy and requirements [32]. These realities determine the impact on the demeanour of the participants on the encounter and asymmetrical power among them. The position of moderators, candidate 01 , and candidate 02 is in triangular, meaning that they can see each other by changing the sight direction and slightly turning the head. The two moderators, Ira Koesno (IK) and Imam Priyono (IP) sit behind a table around a meter from the main stage and three meters from each candidate. The stage is two steps higher than the moderators' floor. IK takes the right chair while IM sits on the left. For each candidate, the president candidates - Joko Widodo (JW) and Prabowo Subianto (PS) - are seated on the right chairs while the vice-president - Amin Ma'ruf (AM) and Sandiaga Uno (SU) - are seated on the left. Directly in far front of the moderators' table, there is a big screen functioned as the background displaying a changed words and pictures. On the left side of moderators, there stand the candidate 01 while the candidate 02 is on the right. Approximately a meter behind the moderators' table, there are lots of chair reserved for invited audience who are categorised as neutral audience: not politically bounded with or publicly declared for any political parties. On the other hand, at the same distance between the moderators and neutral audiences, there are plenty of chairs designed for leaders of coalition parties from each candidate. They are to support the candidates for whatever answer he delivers. Overall, this general physical layout overview can give us a depiction of what will happen during the presidential debate.

In this social encounter, the two moderators always sit in the wishbone chairs. There are some paper on the table to read, pens and two seven-inch tablets in front of each. They speak through omnidirectional earset microphone which is put in their head. This device gives them freedom to speak without having to move their body to grab and speak in a microphone. A relatively more freedom of moving, however, is provided for the candidates. In each of their position, there are two comfortable slipper chairs side by side separated by a coffee table. On the table, there are two glasses of water and some paper. During the advertisement breaks, the candidates may take a rest on the slipper chairs while receiving some briefings from their team. A meter of distance in front of the chairs, there are two lectern podiums equipped with podium microphones, albeit there is a clip-on microphone attached to their clothes on the chest. It means that during the occasion of talk, the candidates should stand behind the lectern 
podium and speak through the podium microphones that must be adjusted with their height preference.

The moderators are wearing formal clothes: navy blue lady blazers with pant for IK and grey men suit for IP. Candidate 01 differs in costume with candidate 02 significantly as, perhaps, this is how voters should recognize them: plain white and suit consecutively. Both JW and AM wear black skull cap, white shirts, and dark trousers. Interestingly, AM puts a white scarf around the neck which signifying a religious leader. In another side, candidate 02 represents themselves in formal outfit: black suit jacket. PS and SU wear black skull cap, double breasted suit for PS and single breasted suit for SU, with white shirt and red tie on it. The supporters who sit behind the candidates also need to distinguish. For candidate 01, the supporters wear a uniform of navy blue bomber jacket with some emblems attached. However, the supporters are more colourful in candidate 02: they wear different types and colours of cloth representing their party's colour identity. The neutral audiences also show their neutrality in term of clothing. Most of them wear batik as a safe option in this formal encounter.

The posture of participants also should be considered as well. Throughout the debate, the moderators are sitting in wishbone chairs and put their hands on the table. Despite of their sitting position, they hold power and authorities to control the floor and to make sure that the debate runs smoothly by signing of moving hands, for example. The two candidates own two positions: sitting while advertisement breaks and standing when a session goes on. Standing behind the lectern podium allows them to move freely, especially in making bodily gestures. They put their hands on the slant-topped high desk and adjust the microphone as needed. Unfortunately, the recording does not show the scene when the candidates are sitting on the chairs. Other participants in this social encounter are the audience - either members of party of neutral audience - and tv crews. Audience are positioned to sit in the chairs provided but in different arrangement. The members of party are sitting behind each candidate in theatrical stance. This setting enables them to be clearly visible from neutral audience and gives them a free-obstacles orientation. On the other hand, the neutral audience who are sitting behind the moderatos are arranged in a level position which probably hinders the visibility of rear audiences. The tv crews, despite invisible during the recording, they do exist in the encounters and they are standing all the time further away from the stage. It should be remembered that neither the audience nor the tv crews have power and freedom in this encounter. They are strictly bound to certain rules of frames and they must obey it during the encounter.

The movement of eyes among ratified participants is other predominant realities. Throughout the four-minute recording, the moderators can flexibly move their head to observe the surrounding of both on and off stage. They cannot see the candidates directly all at once due to the triangle position. They turn their neck to the candidate they wish to speak to and swivel the chairs in managing the audiences. The candidates also have a flexibility of looking, directing their head either to the rival or to the moderators. Interestingly, most of the time, PS straightly directs his head pointless facing the camera instead of to the rival or the moderators. This empty gaze will probably contribute to the participation status of the encounter.

Establishing a rigid limitation is essential in understanding the role of each participants in an encounter as what Goffman [12] calls as participation framework. As a conceptual apparatus in footing alterations [26], Goffman differentiates participants between ratified and unratified (bystander). Ratified participants mean that their presence is known and be part of the conversation. It means that all the audiences who come to the place of debate are part of encounter. This status comprises two types, i.e. speaker and hearer. Individuals who may speak, and are speaking in the short clip, are moderators and the candidates. The speaker is 
divided into three smaller parts: animator, author, and principal. These social roles greatly depend on particularly frame and code switching. Each of them has dissimilar roles in the production format. The hearer, as the same, is mentioned in two sides: addressed and unaddressed. Meanwhile, Goffman classifies the unratified participants - having no right to take part in the conversation - into overhearer and eavesdropper. I conclude that the audience who are not presented in the same place and time and who are not involved in live conversation is the unratified participants.

In this presidential debate - particularly in this four-minute data recording - there is a limitation of swap roles among the participants. Swapping the talk between the candidates is deemed as an infringement of frame. In the early recording, IK waves her right hand to give sign to all hearers for the following session of the debate. She directs the topic of discussion to candidates by emphasizing her production by saying deference to candidates. Her social roles are combination between author and animator which, in turn, the code switch changes rapidly in an utterance. It shows that there are changings of canonical pattern in this encounter.

Table 1. The canonical pattern of video fragment from the presidential debate

\begin{tabular}{lllllllll}
\hline \multicolumn{2}{c}{ Ratified participants } & $\mathbf{1}$ & $\mathbf{2}$ & $\mathbf{3}$ & $\mathbf{4}$ & $\mathbf{5}$ & $\mathbf{6}$ & $\mathbf{7}$ \\
\hline $\begin{array}{l}\text { Speaker } \\
\text { Others }\end{array}$ & Addressed & IK & IK & IK & JW & IK & JW & IK \\
& & JW\& & JW & PS & JW & IK & PS \\
& Unaddressed & - & $\begin{array}{l}\text { PS } \\
\text { audie }\end{array}$ & $\begin{array}{l}\text { audie } \\
\text { nce }\end{array}$ & $\begin{array}{l}\text { audie } \\
\text { nce }\end{array}$ & $\begin{array}{l}\text { audie } \\
\text { nce }\end{array}$ & $\begin{array}{l}\text { audie } \\
\text { nce }\end{array}$ & $\begin{array}{l}\text { audie } \\
\text { nce }\end{array}$ \\
\hline
\end{tabular}

The main participants in this encounter are IK, JW, and PS who are involved in the series of interchanges conversation. Both the candidates are able to speak in a limited time allocation when spoken to, yet they do not have right to self-select for the next turn.

Early of the recording, IK recognizes all audiences as ratified participants by saying "Kita akan lanjutkan kembali" (we will continue) at 00.02 which signifies code-switchinglike behaviour without involving a code switch, or it is precisely immediate behaviour [12]. The subsequent utterance becomes specifically directed to the candidates to introduce the theme of debate. The following turn is given to candidate 01 as JW is pointed out to speak to. The IK's left pointing hand signifies an emphasizing of occasion and time allocation. Once JW receives the chance of speaking, he acts himself as animator: reading a written question which is put on the table. While reading the statement and question, he occasionally turns his head and look at PS, but rarely sees the moderator. His physical gesture of emphasizing becomes more salient in stating the question to PS by pointing the right hand-index finger, stressing tone of intonation, and glaring at PS for more than 10 seconds. Apparently, JW expends all his determination to specifically address PS.

Interestingly, however, the reciprocal bodily expression of PS denotes half de-ratification of the candidates 01 and shows his hesitancy refutation answer. Gazing in conversational alignment considers as giving deference to the position of interlocutors. Due to the spontaneous response, PS looks frantic in delivering the answer. Initially, he does not look at JW as the animator, but instead pointing his face straightforwardly to the camera, perhaps. His status as author brings about unstructured utterances on the two-minute response session. Pause filler "baik" (alright) at 01.08 as the first word produced implies the process of mind to construct the ideas by absorbing the new information combined with preserved experience. Unfortunately, his straight view - instead of looking at JW or moderators - is not 
accompanied with convincing utterance structure. He turns his head occasionally to have an eye contact with candidates 01 and rarely to the moderators. Lack of giving attention to JW and directing face forwardly implies in two exegesis: 1) de-ratifying JW in this encounter as the political rival, or 2) ratifying the bigger-sized unratified participants who do not share on the same place of presidential debate. In the middle of answer, finding the locus of statement, he rises the voice and accentuates selected words. Overall, for the matter of fact, his statement to previous query violates the Grice's maxim of relevant: giving information as informative as possible.

An intertwined footing happens between IK and PS owing to the pause of PS statement around 5 seconds. It is the moderators who have right to take turn of the following conversation above all participants without any objection. IK confirms whether PS still wants to continue the answer as he has remaining allocated time. Once PS said "cukup" (enough) at 02.24, IK takes the turn to let candidate 01 for giving feedback. Surprisingly, not having finished the instruction, IK is suddenly interrupted by PS just to make sure, again, that his party fights against corruption. IK stops her instruction for a while because, albeit she totally controls the floor, it is still the time allocation of PS to speak and this is her obligation not to disallow him. Having given a chance of speaking to PS, IK invites JW to respond over the answer of PS. Up to this point, the turn takings among the participants are quit complex because of the diversity of participants, including how the moderators should warrant the audience to calm down and threaten not to continue the session otherwise the audience can control themselves.

It should be the time for JW to respond the previous answer. He commences the utterance at 02.40 by saying apology and giving deference as a tool to restore the proper participation framework of addressed hearer "mohon maaf, mohon maaf Pak Prabowo" (sorry, sorry mister Prabowo). Instead of countering the answer, JW prefers to restate the question in such a way that is easier to understand. The use of downward pointing hand, raising intonation, and glaring successfully provokes an attempt of distraction to intercept further statement. Unexpectedly, while there is 35 seconds left for JW to speak, the contender cuts off JW's statement by an initiatively turn taking attempt as though PS wanted to re-counter the respond by saying "pak" (sir) at 03.09 and turning head and looking at JW for a few seconds. The immediate interruption is the result of blaming and accusation at 03.06 "artinya bapak tandatangan" (it means you put your signature) on the topic of discussion. Having known that it is such a prohibited turn taking, PS confirms the moderators whether he may answer the responds. This asking permission is part of returning on track upon conversational alignment by adjusting the frame. The action, however, unexpectedly generates laughter from the audience from both candidates' party leader and neutral one.

IK sprightly takes control the turn taking interlude and then asks whether JW has finished the allocated time using. There is a pause between the invitation to speak and acceptance of speaking followed by fading out of audience's laughter which then, all at sudden, again, PS occupies this occasion to distract or, presumably, melts the heating up situation. He moves his arm, shoulder and head accompanied by smiling face as though he showed a feeling of innocent realized by dancing-like movement. Regarding the bodily movement as funny, an even louder laughter come from the audience. It makes IK work harder in making strategic decisions to control the floor by holding back the session, freezing the allocated time of JW, and inviting the audience to give applause. This is the best immediate action of her to take in this situation. At the same time, SU who stands on the left side of PS tries to cool down the tension of PS's guilty in turn taking by touching his upper back with the right hand as a mean of sending support. SU continues to put his both hands on PS's shoulder and starts massaging 
for 6 times and ends the action with a slow pat on the right upper back. IK succeeds in managing the floor properly, albeit there is speech collision between IK who wants to invite JW to speak to and JW who wants to clarify his statement to PS. At this point, JW de-ratifies IK as bystander of the alignment by seeing PS while he is speaking and ratifies PS as address of the hearer by turning head to him. These three participants accordingly create an interactive asymmetry reciprocally through the canonical events of encounter.

An enactment of power asymmetry obviously appears on this session represented by of what IK does: deciding the precise moment of speaking, commencing and ending the allocated time, and selecting for the next turn [17]. Although JW is the current president of Indonesia, IK unhesitatingly halts the time of speaking once the bell rings. This is her efforts to stay on the rule of frame and maintain the footing through the social encounter albeit the flouting of maxim appears. In this respect, both candidates really want to convey their political ideas and convince the potential voters throughout the best impression of presidential debate which is broadcasted nationally. They believe that ratifying the unknown unratified participants in their production format of presidential debate will, to some degree, leverage their potential votes in the election day. This is in accordance with what Goffman [12] proposes as the dichotomy of audience in broadcast talk: live audience and broadcast audience.

\section{Conclusions}

Based on these findings and explanations it can be argued that interaction of participants is closely tied up with the surrounding realities which then it constructs certain frame. In this case, the presidential debate fragment video - as a part of Indonesian presidential run undergoes some twisted frame which, in turn, affects the alteration of footing amongst three participants. Unfortunately, the participation framework of the social frames exemplifies a talk domination power of one participant upon others through strictly order of sequences which results in unbalanced and unnatural social interaction. Unpreparedness of participant in responding the turn taking brings about flouting Grice's maxim of relevant. As the matter of fact, PS answers the JW's query in an unstructured sentence and pointless statement. As to remember that, under the notion of production format, JW acts as animator while PS acts as author. Lastly, despite the live audience in the stage of broadcast as ratified participants, there are unratified participants who are deemed by candidates to be more important for their run than the live audience, i.e. broadcast audience.

\section{Acknowledgements}

I would like to express my gratitude to Jim O'Driscoll for his insight and suggestions on this paper. I am indebted to School of Music Humanities and Media, University of Huddersfield for the financial support in this conference. My thanks also goes to Ministry of Religious Affairs of Republic of Indonesia for having granted me as one of the MORA scholarship awardees. I am also thankful to the board of editors for giving me feedback on this paper. 


\section{References}

[1] E. Goffman, Forms of Talk, Philadelphia: University of Pennsylvania Press, 1981.

[2] K. H. Jamieson and D. S. Birdsell, Presidential Debates: The Challenge or Creating an Informed Electorate, Oxford: Oxford University Press, 1988.

[3] A. Schroeder, Presidential Debates: Forty Years of High-Risk TV, New York: Columbia University Press, 2000.

[4] F. Stecker, The Podium, The Pulpit, and The Republicans: How Presidential Candidates Use Religious Language in American Political Debate, California: Praeger, 2011.

[5] J. M. Atkinson and J. Heritage, Structures of Social Action: Studies in Conversation Analysis, J. M. Atkinson and J. Heritage, Eds., Cambridge: Cambridge University Press, 2003.

[6] E. Goffman, "The Neglected Situation," American Anthropologist, vol. 66, no. 6, pp. 133-136, 1964.

[7] S. D'hondt, "The Pragmatics of Interaction: A Survey," in The Pragmatics of Interaction, Amsterdam, John Benjamins Publishing Company, 2009, pp. 1-19.

[8] E. Goffman, Interaction Ritual: Essays on Face-to-Face Behavior, New York: Pantheon, 1967.

[9] J. O'Driscoll, "Dances with Footings: A Goffmanian Perspective on The Soto Case," Journal of Politeness Research, vol. 14, no. 1, pp. 39-62, 2018.

[10] E. Goffman, Frame Analysis: An Essay on the Organization of Experience, Boston: Northeastern University Press, 1986.

[11] E. Goffman, Behavior in Public Places: Notes on the Social Organization of Gatherings, New York: The Free Press, 1963.

[12] A. Ekström, "Epistemic Positioning and Frameworks for Participation: Learning to Assess Objects of Craft in Teacher Education," Learning, Culture and Social Interaction, vol. 2, pp. 277-292, 2013.

[13] B. L. Heisterkamp, "Taking the Footing of a Neutral Mediator," Conflict Resolution Quarterly, vol. 23, no. 2, pp. 301-315, 2006.

[14] A. Agha, "Voice, Footing, Enregisterment," Journal of Linguistic Anthropology, vol. 15, no. 1, pp. 38-59, 2005.

[15] A. Kyratzis and L. d. Leon, "Framing, Footing, and Language Scaling Practices in Children's Multilingual Peer and Sibling-Kin Group Interactions: An Introduction," Journal of Pragmatics, vol. 144, pp. 70-77, 2019.

[16] D. Skidmore and K. Murakami, "How Prosody Marks Shifts in Footing in Classroom Discourse," International Journal of Education Research, vol. 49, pp. 69-77, 2010.

[17] C. Antaki, F. Diaz and A. F. Collins, "Keeping Your Footing: Conversational Completion in ThreePart Sequences," Journal of Pragmatics, vol. 25, pp. 151-171, 1996.

[18] E. A. Schegloff, "Sequencing in Conversational Openings," American Anthropologist, vol. 70, no. 6, pp. 1075-1095, 1968.

[19] E. Ytreberg, "Erving Goffman as a Theorist of the Mass Media," Critical Studies in Media Communication, vol. 19, no. 4, pp. 481-497, December 2002.

[20] I. Hutchby, "Frame Attunement and Footing in the Organisation of Talk Radio Openings," Journal of Sociolinguistics, vol. 3, no. 1, pp. 41-63, 1999.

[21] G. W. Smith, "Enacted Others: Specifying Goffman's Phenomenological Omissions and Sociological Accomplishements," Human Studies, vol. 28, pp. 397-415, 2006.

[22] J. Cromdal and K. Aronsson, "Footing in Bilingual Play," Journal of Sociolinguistics, vol. 4, no. 3 , pp. 435-457, 2000.

[23] M. Dynel, "Participation Framework Underlying YouTube Interaction," Journal of Pragmatics, vol. 
73, pp. 37-52, 2014.

[24] M. Dynel, "Revisiting Goffman's Postulates on Participant Statuses in Verbal Interaction," Language and Linguistics Compass, vol. 5, no. 7, pp. 454-465, 2011.

[25] S. D'hondt, "Defending Through Disaffiliation: The Vicissitudes of Alignment and Footing in Belgian Criminal Hearings," Language and Communication, vol. 36, pp. 68-82, 2014.

[26] J. Turcotte and R. K. Goidel, "Political Knowledge and Exposure to The 2012 US Presidential Debates: Does Debate Format Matter?," PS: Political Science and Politics, vol. 47, no. 2, pp. 449453, 2014

[27] K. Driscoll, A. Leavitt, K. L. Guth, F. Bar and A. Mehta, "Beyond Big Bird, Binders, and Bayonets: Humor and Visibility Among Connected Viewers of the 2012 US Presidential Debates," Social Media + Society, pp. 1-12, January-March 2018.

[28] K. J. Mullinix, "Presidential Debates, Partisan Motivations, and Political Interest," Presidential Studies Quarterly, vol. 45, no. 2, pp. 270-288, 2015.

[29] P. R. Schrott and D. J. Lanoue, "The Power and Limitations of Televised Presidential Debates: Assessing The Real Impact of Candidate Performance on Public Opinion and Vote Choice," Electoral Studies, vol. 32, pp. 684-692, 2013.

[30] M. H. Jacobsen and S. Kristiansen, The Social Thought of Erving Goffman, Los Angeles: SAGE Publications, 2014.

[31] J. O'Driscoll, "Situational Transformations: The Offensive-izing of an Email Message and The Public-ization of Offensiveness," Pragmatics and Society, vol. 4, no. 3, pp. 369-187, 2013 a.

[32] J. O'Driscoll, "The Role of Language in Interpersonal Pragmatics," Journal of Pragmatics, vol. 58, pp. 170-181, 2013b. 